\title{
A Rare Cause of Vaginal Discharge in a Pre-Pubertal Girl
}

\author{
Koushik Herle, Harshjeet Singh Bal*
}

Department of Pediatric Surgery, Christian Medical College, Vellore, Tamil Nadu, INDIA

\section{ABSTRACT}

Vaginal discharge is not an uncommon gynaecological problem and is most commonly infective in origin. Foreign bodies in vagina are the most common non-infective cause of vaginal discharge. We report a case of 5-year-old girl with button battery in vagina causing walled off collection along with vaginal discharge. Child needed a laparotomy due to the dense synechiae caused by the battery leak.

Key words: Button battery; Vaginal foreign body; Vaginal discharge

Correspondence*: Dr Koushik, Department of Paediatric Surgery CMC. VELLORE

E-mail: koushik.herle@gmail.com

(C) 2017, Herle et al

Submitted: 13-05-2017

Accepted: 10-06-2017

Conflict of Interest: None

Source of Support: Nil

This is an open-access article distributed under the terms of the Creative Commons Attribution License, which permits unrestricted use, distribution, and reproduction in any medium, provided the original work is properly cited.

\section{INTRODUCTION}

Vaginal discharge secondary to a foreign body accounts for about $4-5 \%$ of all outpatient visits in gynaecological practice.[1] Toilet paper, bottle caps, button battery, and toys are the foreign bodies reported in literature.[2]. Prepubertal girls have higher risk of injury from vaginal alkaline battery in view of their pre-existing alkaline $\mathrm{pH}$ and low estrogen state. Tissue damage occurs from leakage of potassium and sodium hydroxide which raises the $\mathrm{pH}$ close to 11 in addition to electrical discharge and pressure necrosis.[3] We herein report an interesting case of button battery in vagina.

\section{CASE REPORT}

A 5-year-old girl presented with the complaint of blood stained vaginal discharge for 20 days. Previously she had whitish vaginal discharge occurring intermittently for the past one year. On inspection, there was no obvious lesion found. Ultrasound and CT scan, performed elsewhere, showed a cystic mass $(3 \times 2 \times 3 \mathrm{~cm})$ present in the pelvis behind the urinary bladder. The mass was hyper dense on CT and was reported to be a dermoid cyst with calcification (Fig.1). On per rectal examination a tense smooth cystic structure felt anterior to rectum with an intact rectal wall. Beta HCG and AFP serum markers levels were in normal range.

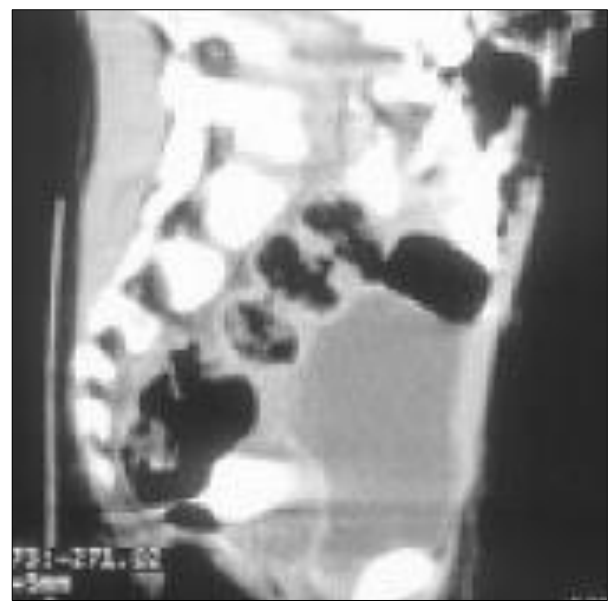

Figure 1: Scout image of CT abdomen showing the battery.

Genitoscopy showed a dense vaginal synechiae in the mid-vagina. Cervix could not be visualised. Diagnostic laparoscopy showed a smooth retro-vesical cyst. Uterus 
and ovaries were normal. There was suspicion of a foreign body in vagina but the same was not visualised. On exploration, the cyst was present behind the bladder adherent to the vagina. It was difficult to find dissection plane between the cyst and the vagina. The anterior cyst wall was then opened which contained $20 \mathrm{cc}$ of pus. It was noticed that the closed cavity was formed between cervix and fornices of vagina cranially and the dense synechiae between anterior and posterior walls of vagina caudally (Fig.2). A button battery was found in the cavity. The synechiae were released. The burnt vaginal wall appeared hyperemic. Postoperatively the child had an uneventful recovery. At follow-up patient is fine.

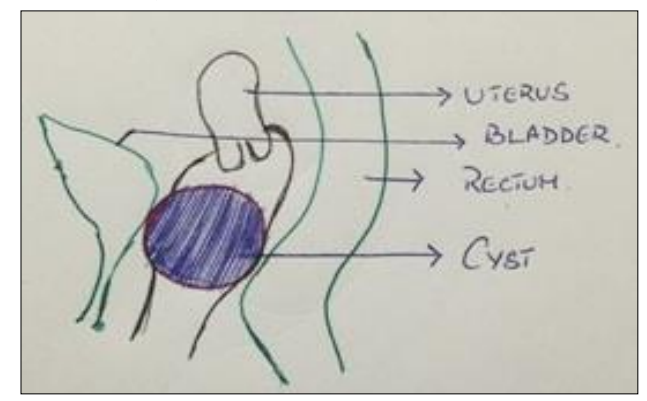

Figure 2: Diagrammatic representation of the cyst

\section{DISCUSSION}

Vaginal foreign bodies are mainly self-inserted.[4]. A prudent clinical history along with imaging and ultrasonography are important diagnostic tools. Genitoscopy is used both for diagnosis and its removal however, it was not done in our case owing to presence of a pelvic cystic mass. High index of suspicion and good clinical examination including vaginoscopy is a must in clinching the diagnosis of vaginal foreign body in patients with vaginal discharge.

Consent: Authors have submitted signed consent form from legal guardians of the patient for use of clinical material in this manuscript. The Consent form is available with Editorial office.

Authors' Contribution: Both authors contributed equally in concept, literature review, and drafting of the manuscript. Both authors approved the final version of this manuscript.

\section{REFERENCES}

1. Paradise JE, Willis ED. Probability of vaginal foreign body in girls with genital complaints. Am J Dis Child. 1985;139:4726.

2. Fard SE, Hojati HN, Paydary K, Tajali A. Vaginal bleeding due to insertion of button battery : a case report and review of literature. Thrita. 2014;3:20-2.

3. Huppert J, Griffeth S, Breech L, Hillard P. Vaginal burn injury due to alkaline batteries. J Pediatr Adolesc Gynecol. 2009;22:133-6.

4. Griffin K, Brent R, Vollenhoven B, Swanson AE. Vaginal burn from alkaline battery in an 8-year-old. J Pediatr Adolesc Gynecol. 2015;28:e99-100. 